\title{
Naturally Occurring Surface Antigen Variants of Hepatitis B Virus in Tunisian Patients
}

\author{
Houda Chaouch ${ }^{a, c}$ Stefania Taffon ${ }^{d}$ Umbertina Villano $^{d}$ Michele Equestre $^{e}$ \\ Roberto Bruni $^{d} \quad$ Manel Belhadj $^{b}$ Naila Hannachi ${ }^{b} \quad$ Mahjoub Aounic $^{c}$ \\ Amel Letaief ${ }^{a} \quad$ Anna Rita Ciccaglione ${ }^{d}$

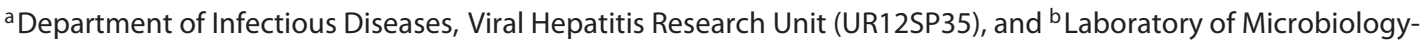 \\ Immunology, UR02SP13, University Hospital Farhat Hached, Sousse, and ' Laboratory of Infectious Diseases and

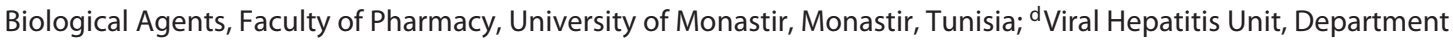 \\ of Infectious, Parasitic and Immune-Mediated Diseases, and e Department of Cell Biology and Neurosciences, Istituto \\ Superiore di Sanità, Rome, Italy
}

\section{Key Words}

Hepatitis B surface antigen mutation - Hepatitis B surface antigen subtype $\cdot$ Major hydrophilic region - Tunisia

\begin{abstract}
In Tunisia, the prevalence of naturally occurring surface (S) gene variants of hepatitis B virus (HBV) has not been determined. In the present study, the prevalence of these variants was examined in terms of the clinical and viral state in a series of 99 Tunisian patients with HBV infection. The $S$ genes were amplified and directly sequenced. Genotype D was predominant (98\%), $40.4 \%$ isolates belonged to subgenotypes D7 and 1 to subgenotype D2. The most common subtype was ayw2 (95.9\%). In total, $60.6 \%$ of the studied strains harbored $\mathrm{S}$ mutations. Several novel mutation patterns were detected. Interestingly, the presence of S mutations was significantly correlated with the D7 subgenotype, low HBV DNA and advancing age ( $\geq 35$ years), and tended to be higher in liver cirrhosis than in chronic infection. The global prevalence of the major hydrophilic region variants was $12.1 \%$,
\end{abstract}

with substitution S143L/T as the most frequent (4\%). Only $33.9 \%$ of $S$ substitutions produced amino acid changes in the polymerase gene. In conclusion, a high prevalence of naturally occurring HBsAg variants was observed among Tunisian HBV carriers. Natural viral variability in a geographical region and duration of infection are among the major factors associated with the occurrence of S mutations.

(c) 2016 S. Karger AG, Basel

\section{Introduction}

Despite the availability of hepatitis B surface antigen (HBsAg) vaccines and mass immunization schemes, hepatitis $B$ virus (HBV) infection continues to be a major public health problem with more than 350 million chronically infected people, some of whom develop liver cirrhosis and hepatocellular carcinoma [1].

$\mathrm{HBV}$ is an enveloped virus belonging to the Hepadnaviridae family. The genome is a small circular partially double-stranded DNA molecule of about $3.2 \mathrm{~kb}$, in-

\section{KARGER}

E-Mail karger@karger.com www.karger.com/int (c) 2016 S. Karger AG, Basel

0300-5526/16/0591-0036\$39.50/0
Houda Chaouch

Service des Maladies Infectieuses

CHU Farhat-Hached

Sousse 4000 (Tunisia)

E-Mail chawech_houda@yahoo.fr 
cluding 4 overlapping open reading frames (ORF). HBV displays remarkable genetic diversity, compared to other DNA viruses, related to high levels of virus production and error-prone nature of the reverse transcriptase (RT) polymerase. In addition, host immune systems, passive and active immunization, and antiviral therapy act as selective pressures driving HBV evolution [2]. To date, molecular phylogenetic analyses of HBV have revealed 9 genotypes (A-I) and approximately 40 subgenotypes which exhibit different geographical distribution [3].

$\mathrm{HBsAg}$, the major envelope protein of $\mathrm{HBV}$, is composed of 226 amino acids (aa) and contains a central region called the major hydrophilic region (MHR) from aa 100 to 169 , which is highly immunogenic and is under selective pressure of the immune system. Interestingly, the MHR contains a cluster of major B-cell epitopes located between aa 124 and 147, termed the 'a' determinant. This highly conserved region is considered the major immune target for antibodies induced by passive or active immunization and used in diagnostic assays [4]. Mutation of HBsAg, particularly within the 'a' determinant, could alter the antigenicity of this protein, leading to neutralization failure of virus by anti-HBs antibody and may cause escaping from the host's immune system $[5,6]$. These mutations can be selected under immune pressure during the course of HBV infection [7, 8], either within or outside the MHR region [9-11].

Understanding the prevalence and diversity of $\mathrm{HBsAg}$ variants is of high importance, because this will affect policy decisions relating to vaccine and diagnostic reagent design [12]. However, the prevalence of $S$ mutations is still unknown in many geographical regions. De Maddalena et al. [13] found that genotype D strains carry more mutations in the 'a' determinant with potential escape mutants in nonvaccinated subjects. Therefore, they indicate the need for careful surveillance of these variants in areas in which genotype $\mathrm{D}$ predominates. Tunisia is a country with an intermediate HBV endemicity; the prevalence of HBsAg ranges from 4 to 7\% [14] with predominance of genotype D $[15,16]$. However, to date there has been a lack of data on the genetic diversity of HBsAg from $\mathrm{HBV}$ isolates circulating in Tunisia. The prevalence of HBsAg polymorphisms is still unknown and should be recorded.

The aim of the present study was to determine the prevalence of naturally occurring HBsAg polymorphisms and describe the specific mutation patterns in a significant number of HBV strains isolated from Tunisian patients.

HBs Antigen Mutants in Tunisia

\section{Materials and Methods}

\section{Patient Samples}

The study population included $99 \mathrm{HBV}$ chronic carriers selected from patients followed for hepatitis B infection, in the Department of Infectious Diseases at Farhat Hached University Hospital in Sousse, during the period from 2010 to 2014. The diagnosis of $\mathrm{HBV}$ infection was based on a positive result of HBsAg for at least 6 months and a positive result for HBV DNA. Exclusion criteria were: coinfection with hepatitis $\mathrm{C}$ virus (HCV), hepatitis $\mathrm{D}$ virus and human immunodeficiency virus. None of the patients were vaccinated for $\mathrm{HBV}$ or had received antiviral or immunoglobulin therapy. The serum samples from all patients were stored at $-20^{\circ} \mathrm{C}$ until analysis. The study was reviewed and approved by the Ethics Committee of Farhat Hached University Hospital.

\section{Serological and HBV DNA Quantitative Assays}

Hepatitis B virus markers (HBsAg, anti-HBs, anti-HBc total, $\mathrm{HBeAg}$, anti-HBe) and HCV (anti-HCV) were detected by microparticle enzyme immunoassay technology (AxSYM; Abbott Laboratories, Abbott Park, Ill., USA). Liver function tests, including alanine aminotransferase and aspartate aminotransferase, were measured using commercially available autoanalyzers. HBV DNA levels were quantified by a commercial real-time PCR (COBAS AmpliPrep/COBAS TaqMan, Roche Diagnostics); the detection limit was $12 \mathrm{IU} / \mathrm{ml}$.

\section{Extraction of $H B V D N A$, Amplification and Sequencing of}

Surface Gene

Viral DNA was extracted from $200 \mathrm{ml}$ serum using the EZ1 Virus Mini Kit v.2.0 (Qiagen, Hilden, Germany) following the manufacturer's instructions. HBV DNA was amplified by polymerase chain reaction (PCR), as previously described [17], with the platinum Taq DNA polymerase (Invitrogen, Life Technologies Corporation, Monza, Italy). The PCR products were purified using the Amicon ${ }^{\circledR}$ Ultra-0.5 Centrifugal Filter Devices in accordance with the manufacturer's instructions. Sequencing reactions were performed using the Genome Lab DTCS Quick Start Kit (Beckman Coulter Inc., Fullerton, Calif., USA) and were run on an automated DNA sequencer (Beckman Coulter Inc.). PCR and sequencing were possible only for serum samples with a viral load above 2,000 $\mathrm{IU} / \mathrm{ml}$. A fragment of the $\mathrm{S}$ gene, which comprised codons 33-226 of the HBsAg molecule, was selected for analysis.

\section{Sequence and Phylogenetic Analysis}

Sequence analysis was performed with Chromas software and BioEdit Package. For the phylogenetic analysis, the 99 sequences obtained in this study were aligned with representative reference sequences of all known HBV genotypes and different subgenotypes of genotypes D (D1-D8) and A (A1-A6) imported from the GenBank database. The sequences were aligned using the ClustalW program incorporated in BioEdit sequence alignment software. Genetic distance was estimated using the Kimura two-parameter model, and the phylogenetic tree was constructed using the neighbor-joining algorithm in the MEGA software. The reliability of the phylogenetic tree was tested by bootstrap analysis with 1,000 replicates. The $S$ gene sequences generated in this work have been deposited in the GenBank database under accession numbers 1TunSO_14 to 102TunSO_14. 
Table 1. Characteristics of the patients and HBV isolates with and without $\mathrm{S}$ mutations

\begin{tabular}{|c|c|c|c|c|}
\hline Age $^{\mathrm{a}}$, years & $36.4 \pm 11.1$ & $38.4 \pm 11.5$ & $33.4 \pm 9.9$ & $\mathrm{p}=0.03^{*}$ \\
\hline Age $\geq 35$ years $^{b}$ & $51(51.5)$ & $37(61.6)$ & $14(35.8)$ & $\mathrm{OR}=2.9, \mathrm{p}=0.01^{*}$ \\
\hline Gender $(\mathrm{M} / \mathrm{F})^{\mathrm{b}}$ & $52 / 47$ & $29 / 31$ & $23 / 16$ & $\mathrm{OR}=1.5, \mathrm{p}=0.3$ \\
\hline HBeAg positive ${ }^{\mathrm{b}}$ & $18(18.1)$ & $10(16.6)$ & $8(20.5)$ & $\mathrm{OR}=0.7, \mathrm{p}=0.6$ \\
\hline $\mathrm{ALT}^{\mathrm{a}}, \mathrm{IU} / \mathrm{l}$ & $55.5 \pm 129$ & $58.8 \pm 154.1$ & $50.4 \pm 80.1$ & $\mathrm{p}=0.7$ \\
\hline Cirrhosis $^{\mathrm{b}}$ & $12(12.1)$ & $9(15)$ & $3(7.6)$ & $\mathrm{OR}=2.1, \mathrm{p}=0.2$ \\
\hline \multicolumn{5}{|l|}{ Genotype } \\
\hline A & $1(1)$ & $1(1.6)$ & 0 & \\
\hline $\mathrm{D}$ & $97(98)$ & $58(96.6)$ & $39(100)$ & n.a. \\
\hline \multicolumn{5}{|l|}{ Subgenotype ${ }^{\mathrm{b}}$} \\
\hline \multicolumn{5}{|l|}{ HBsAg subtype } \\
\hline ayw2 & $95(95.9)$ & $56(93.3)$ & $39(100)$ & \\
\hline ayw3 & $2(2)$ & $1(1.6)$ & $1(2.5)$ & \\
\hline adw2 & $2(2)$ & $1(1.6)$ & $1(2.5)$ & n.a. \\
\hline
\end{tabular}

Data are presented as means $\pm \mathrm{SD}$, numbers with percentages in parentheses, or medians with ranges in square brackets. ALT $=$ Alanine aminotransferase; $\mathrm{OR}=$ odds ratio; n.a. $=$ not adopted. ${ }^{*} \mathrm{p}<0.05$.

a Statistical significance was calculated using the two independent samples t test.

${ }^{\mathrm{b}}$ Statistical significance was calculated using the $\chi^{2}$ test.

Identification of HBV Subtype and Variations of S Gene

The nucleotide sequences of each sample were translated into envelope gene aa sequences according to the ORF of the $S$ gene (S ORF). HBsAg subtype was predicted from the aa sequence of the $S$ gene, by a new algorithm [18], which is based on identifying aa at positions 122, 127, 140,159, and 160. For identifying HBsAg variants, deduced aa sequences were aligned and compared with the HBV reference sequence of the same genotype in BioEdit software. As the $S$ gene overlaps completely with the polymerase gene, the deduced aa sequence of the corresponding fragment of the polymerase was analyzed, and effects of HBsAg variations on the polymerase protein were determined by translation of the sequences according to the polymerase ORF (P ORF).

\section{Statistical Analysis}

Statistical analyses were performed using SPSS software. Values were expressed as percentages, median (ranges) or as mean \pm standard deviation when appropriate. Differences between categorical variables were analyzed using Fisher's exact test or the $\chi^{2}$ test. Student's t test was used for continuous variables. Correlation of S variant occurring with demographic and clinical features was identified by univariate and multivariate analyses using a logistic regression analysis. A p value $<0.05$ was considered statistically significant.

\section{Results}

\section{Patient Characteristics}

Ninety-nine patients with chronic HBV infection were studied. The study subjects consisted of $52.5 \%$ males ( $\mathrm{n}=$ $52)$ and $47.5 \%$ females $(n=47)$ with a mean age of 36.4 years and a range of 19-71 years. Among them, 18.1\% were $\mathrm{HBeAg}$ positive, and $12.1 \%$ had liver cirrhosis. Demographic and virological data of patients are illustrated in table 1 .

\section{Identification of HBV Genotypes and Subgenotypes}

Phylogenetic analysis showed that genotype D was predominant, accounting for 98 out of 99 isolates (data not shown). Genotype A was found in only 1 sample. Among the 98 genotype D isolates, 41 (41.4\%) were successfully subgenotyped by a statistically supported phylogenetic tree (fig. 1). Overall, 40/98 isolates belonged to subgenotype D7 (40.8\%) and 1/98 to subgenotype D2 (1\%). For the remaining 57 genotype D isolates (58.1\%), it was impossible to obtain a statistically supported sub- 
37TunMO_12

25TunSF_14

44TunMA_12

-70TunMO_12

8TunMO_12

- 7TunSO_12

20432 Cirrhosis

87 Cirrhosis

51TunMA 12

\begin{tabular}{l}
86 \\
\hline FJ904416-A66a-TUN-D7
\end{tabular}

58TunSB_12

- 31TunSO_12

-13TunSO_12

57TunKI_12

56TunGB_12

- 75TunSO_12
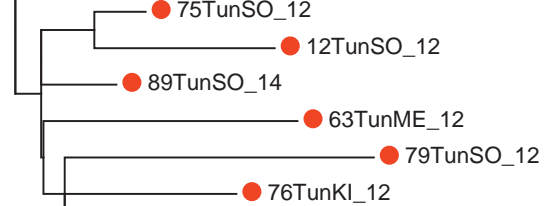

76TunKI 12

52Tunso_12

- 4Tunkl_12

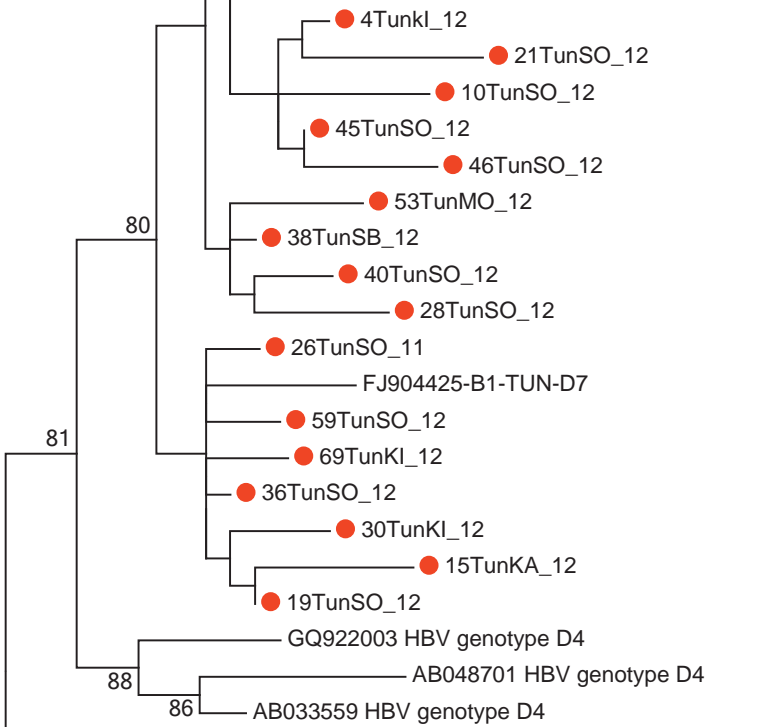

DQ315779 HBV genotype D5

99 GQ205377 HBV genotype D5 AB033558 HBV genotype D5

74 AY233291 HBV genotype D3

95 X65257 HBV genotype D3

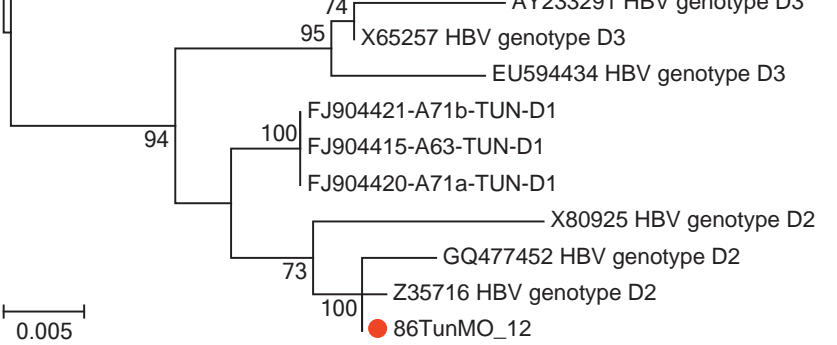

Fig. 1. A phylogenetic tree constructed using the neighbor-joining method, showing D2 and D7 subgenotypes from 41 Tunisian HBV patients. 
genotyping tree as variation in the sequenced region was not high enough to classify these HBV isolates. Thence, all the analyses were performed considering two large subgenotype groups: the 'D7 subgenotype group', including all 40 D7 isolates, and the 'other subgenotype group', including 57 uncharacterized genotype D isolates. The results are summarized in table 1 .

\section{Prediction of HBsAg Subtypes and Association with $H B V$ Genotypes}

The majority of Tunisian HBV strains belonged to the ayw2 subtype (95.9\%, 95/99) based on Arg122, Lys160, Pro127, Tyr134 and/or Gly159. Whereas adw2, based on Lys 122, Lys160, Pro127, Phe134 and Ala 159, was found in only 2 isolates, 1 genotype $\mathrm{D}$ and in the single strain of genotype A. Subtype ayw3, based on Arg122, Lys160 and Thr127, was found in 2 D7 isolates and in the single strain D2. Results concerning HBsAg subtypes are shown in table 1 .

Genotype- and subgenotype-dependent polymorphisms and variations at positions $122,127,140,159$, and 160 were not considered as MHR mutations.

\section{Mutation Analysis of the S Gene in Tunisian HBV Isolates}

Analysis of the $99 \mathrm{HBV}$ Tunisian patients revealed several aa substitutions in the $S$ region that codes aa 33-226. Overall, 346 nucleotide substitutions occurred, of which 115 (33.2\%) were missense (aa mutations), and 231 (66.7\%) were silent (no aa change). In total 60/99 (60.6\%) of the studied strains harbored 115 mutations at 48 different aa positions of HBsAg. Thirty-one (51.6\%) of the strains with aa substitutions showed a single mutation, whereas $29(48.3 \%)$ had a combination of 2-7 mutations.

In univariate analysis, the comparison of clinical and virological characteristics between patients with and without $S$ variants revealed that age $\geq 35$ years was significantly associated with occurrence of $S$ variants $(\mathrm{OR}=$ 2.912, 95\% confidence interval, $\mathrm{CI}=1.245-6.628 ; \mathrm{p}=$ 0.01 ; table 1 ). No significant association with patient sex was detected. In addition, $75 \%$ of D7 subgenotype isolates displayed S mutations, thus making the correlation with this subgenotype highly significant $(\mathrm{OR}=3.000,95 \%$ $\mathrm{CI}=1.242-7.244 ; \mathrm{p}=0.01)$. The correlation between the presence of $S$ mutations and low HBV DNA level $(\leq 10,000$ $\mathrm{IU} / \mathrm{ml})$ was found to be significantly associated $(\mathrm{OR}=$ $2.333,95 \% \mathrm{CI}=1.019-5.342 ; \mathrm{p}=0.04$ ), whereas the correlation with $\mathrm{HBeAg}$ status was not found to be statistically significant $(\mathrm{p}=0.5)$. Although the frequency of mutations was higher in cirrhosis patients, the correlation with cirrhosis did not reach statistical significance $(\mathrm{p}=$ $0.2)$.

In multivariate analysis, D7 subgenotype and low HBV DNA $(\leq 10,000 \mathrm{IU} / \mathrm{ml})$ were found to be significant independent variables associated with the occurrence of $S$ variants $(O R=1.210,95 \% C I=1.039-1.409 ; \mathrm{p}=0.01$; and $\mathrm{OR}=2.924,95 \% \mathrm{CI}=1.224-6.982 ; \mathrm{p}=0.01)$, respectively.

\section{Allocation of Mutations to Surface Protein Immune Epitopes}

The pattern of mutated distribution was established using the published data on the different HBV surface protein immune epitopes [19]. In total, 1, 4 and 4 regions have been proposed for B-cell, T-helper and CTL immune epitopes across the surface protein, respectively. Our results demonstrated that most of the aa substitutions (79.1\%, 91 of 115 mutations) occurred in different antigenic epitopes of the $\mathrm{S}$ gene, with the following distribution: $14(12.1 \%)$ in B-cell epitopes in 8 residues, 26 (22.6\%) in T-helper epitopes CD4+ in 13 residues and 51 (44.3\%) inside CTL epitopes in 15 residues; 24 mutations (20.8\%) were positioned out of these regions.

\section{MHR Mutational Patterns}

Twelve (12.1\%) of 99 patients showed an aa substitution in the MHR region. aa substitution in the 'a' determinant region was observed in 8 isolates $(8 \%)$. Nine isolates displayed only 1 MHR mutation, whereas 3 had a combination of 2 mutations, making the total number of discovered MHR mutations 15. As a result of single base substitution, 9 aa residues were affected: 104, 110, 118, $128,134,138,143,150$, and 169. Interestingly, in $1 \mathrm{HBeAg}$ positive chronic patient (patient 9094 in table 2), a 24-nucleotide deletion was detected in the MHR, affecting 8 codons: s110-s117. No insertion or stop codons were observed in this region.

The most variable position in the MHR was aa 143 with a rate of $4 \%(4 / 99)$, including Ser143Leu and Ser143Thr, each detected in 2 patients with chronic hepatitis B. This degree of diversity is followed by Y134N/F (3\%), L104W (0.99\%), I110L (1\%), T118V (1\%), A128V (1\%), C138G (1\%), I150V (1\%), and R169H (1\%). Different frequencies of mutations within the MHR and other regions of HBsAg are illustrated in figure 2a. Interestingly, an alteration of aa cysteine residues of disulfide bonds in the 'a' determinant at position 138 was detected in 1 chronic infection patient (patient 234 in table 2). aa cysteine residues at positions $124,137,139$, and 147 had no alterations and were considered as conserved positions.
Chaouch et al. 
Table 2. Clinical and virological characteristics of 60 patients with aa substitutions in the HBsAg

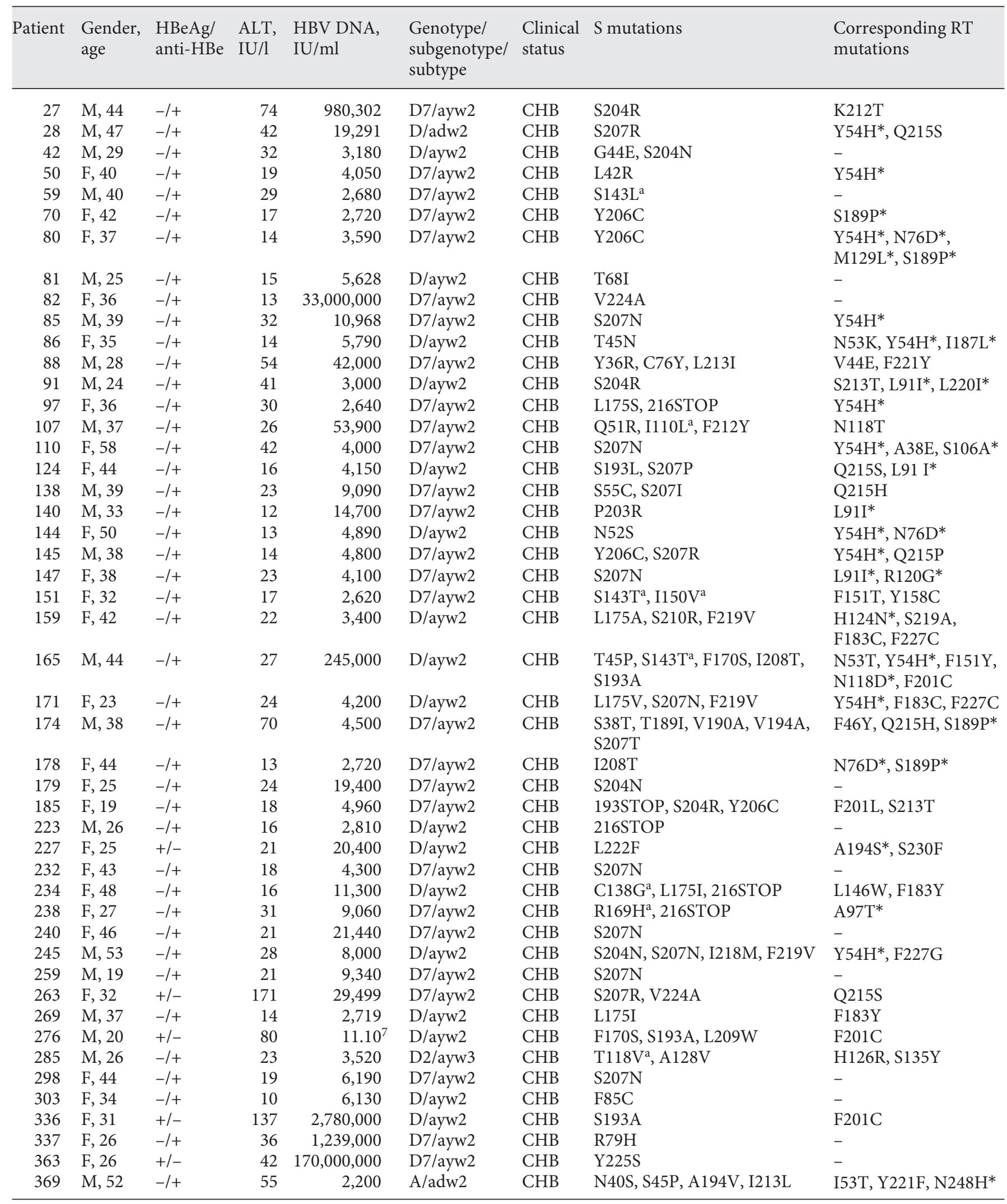


Table 2 (continued)

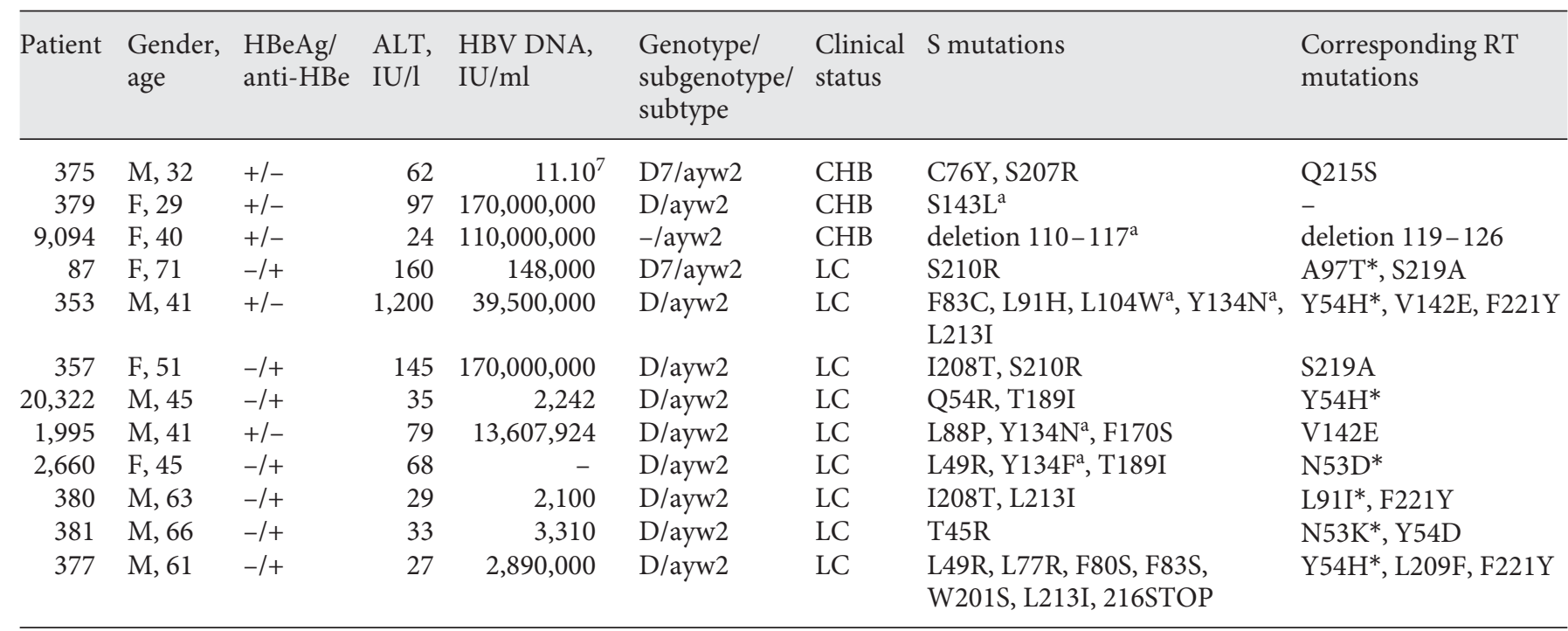

$\mathrm{ALT}=$ Alanine aminotransferase; $\mathrm{CH}=$ chronic hepatitis; $\mathrm{LC}=$ liver cirrhosis; ${ }^{*}=\mathrm{RT}$ silent mutation in HBsAg.

a aa substitution in the MHR region.

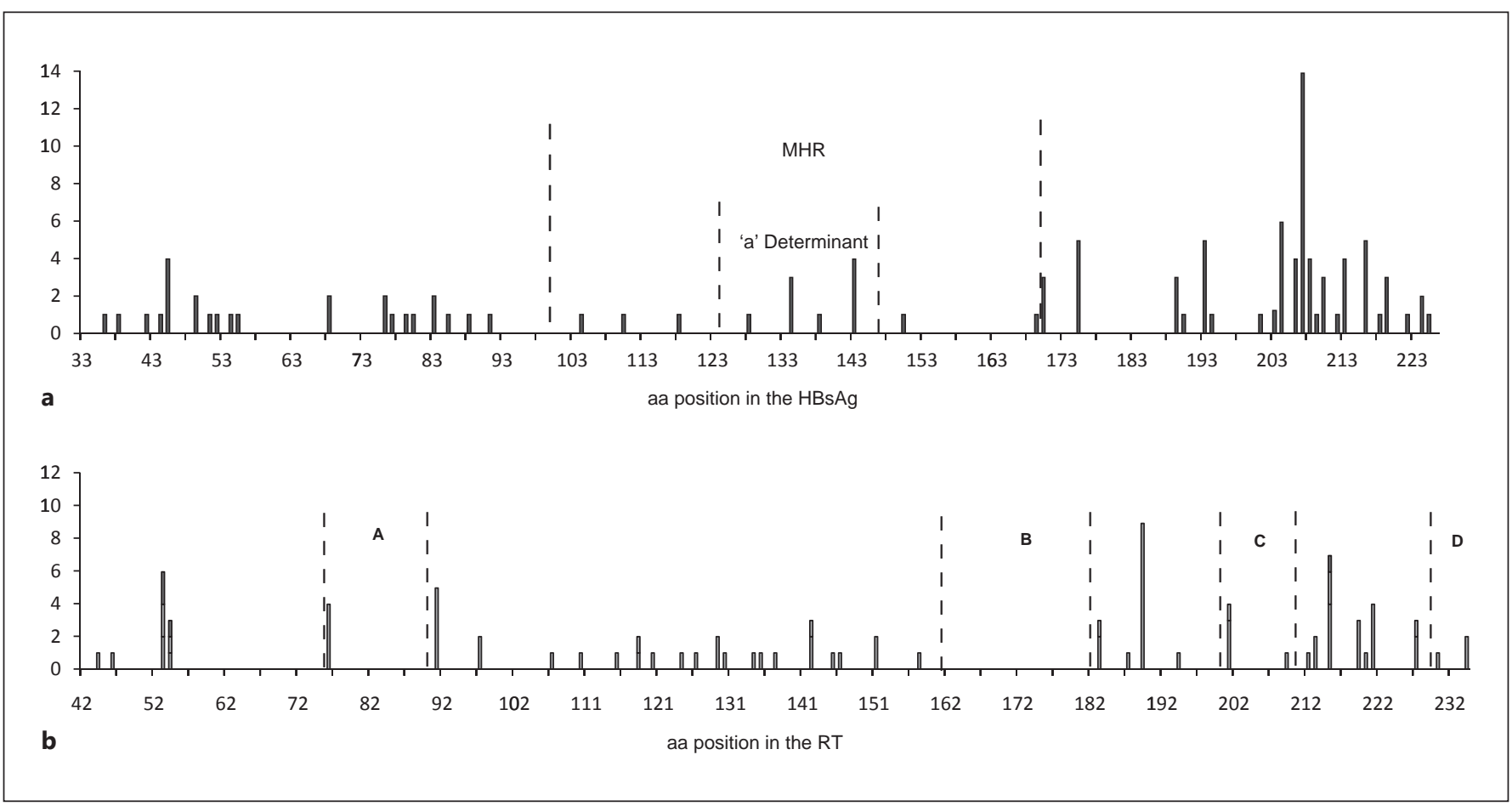

Fig. 2. Character variation of HBsAg and overlapping RT sequence for the 99 clinical isolates. Frequency and distribution of aa substitutions in the HBsAg (a) and overlapping RT sequence (b). The 99 clinical sequences were plotted in the same graph to identify polymorphic and conserved domains. The horizontal axis indicates the aa position of encoded HBsAg protein (aa 33-226) and RT (42232). The MHR and 'a' determinant domain are represented for HBsAg; A, B and C domains are represented for RT. The vertical axis indicates the frequency of aa variation at each aa position. 
Table 3. Biochemical characterization of aa within the MHR and their clinical importance in wild-type and mutant variants

\begin{tabular}{|c|c|c|c|c|c|c|}
\hline 104 & Leu & $\operatorname{Trp}$ & - & - & - & This study \\
\hline 110 & Ile & Leu & Yes & n.d. & n.d. & Katsoulidou et al. [64], 2009 \\
\hline 118 & Thr & Val & - & - & - & This study \\
\hline 128 & Ala & Val & Yes & n.d. & n.d. & Katsoulidou et al. [64], 2009 \\
\hline 138 & Cys & Gly & - & - & - & This study \\
\hline \multirow[t]{2}{*}{143} & Ser & Thr & Yes & n.d. & n.d. & Katsoulidou et al. [64], 2009 \\
\hline & Ser & Leu & yes & Yes & n.d. & Avellon and Echevarria [30], 2006 \\
\hline 150 & Ile & Val & - & - & - & This study \\
\hline 169 & $\underline{\text { Arg }}$ & $\underline{\text { His }}$ & n.d. & n.d. & n.d. & Pourkarim et al. [65], 2014 \\
\hline
\end{tabular}

Basic aa are underlined, hydrophobic aa are in italics, and hydrophilic aa are in bold. n.d. = Not determined.

The biochemical characterizations of aa in wild types and mutants in the MHR, along with their known functional effects, are illustrated in table 3. The variants involved in a failure of HBsAg detection were found in samples of 7 patients $(7 \%, 7 / 99)$. The variants associated with vaccine escape were detected in samples of 2 patients $(2 \%$, $2 / 99$ ), whereas variants involved in immunotherapy escape were detected in 1 patient $(1 \%, 1 / 99)$.

No significant correlation was found between mutations in the MHR and other clinical and virological characteristics, including age $(\mathrm{p}=0.7)$, sex $(\mathrm{p}=0.8)$, alanine aminotransferase level $(\mathrm{p}=0.3), \mathrm{HBeAg}$ status $(\mathrm{p}=0.2)$, cirrhosis $(\mathrm{p}=0.1)$, genotype $(\mathrm{p}=1)$, and HBV DNA levels $(\mathrm{p}=0.5)$ (data not shown).

\section{aa Mutations Outside the MHR}

This analysis revealed several aa substitutions outside the MHR region. In total 100 (86.9\%) of the 115 detected $\mathrm{S}$ mutations occurred outside the MHR. Forty-nine isolates displayed only mutation outside the MHR, whereas 7 had a combination of mutations outside and inside the MHR, making the total number of patients with outside MHR mutations 56 (56.5\%). As a result of single base substitution, 41 different aa positions outside the MHR were affected (fig. 2a), the most variable position was aa 207, for which mutations were present in 16 out of 99 strains (16.1\%). Six stop codons were found upstream of the MHR, 5 in position 216 and 1 at position 193 (results do not correlate with either biochemistry or serology status of the patients). No insertion or deletion was observed in these regions.

HBs Antigen Mutants in Tunisia
Of the 115 aa substitutions in the S gene, 39 (33.9\%) produced aa changes in the polymerase gene (table 1$)$. In addition, 60 RT silent mutations in HBsAg were found; none caused substitution on the $S$ protein. No change was observed in the YMDD motif. Substitution $\mathrm{rtQ} 215 \mathrm{~S} / \mathrm{P} / \mathrm{H}$ corresponding to sS207R/P/I, discovered in 7 strains, was the only provided antiviral resistance-associated mutation detected. $\mathrm{B}$ and $\mathrm{C}$ domains of the RT present very few polymorphisms, despite aa variability of overlapping HBsAg frame (fig. 2b).

\section{Discussion}

Phylogenetic analysis showed the predominance of genotype $\mathrm{D}$ in the Tunisian population which was detected in $98 \%$ of cases. This result is in accordance with previous studies showing a predominance of genotype $\mathrm{D}$ in Tunisia [15, 16] and in the Mediterranean region [3]. Isolates from 41 of the 99 patients (41.4\%) were successfully subgenotyped. Overall, 40 isolates belonged to subgenotypes D7 (40.4\%) and 1 to subgenotype D2 (1\%). Subgenotype D7 was recently described and found prevalent in Tunisia and in Morocco [16, 20], suggesting to be the most predominant in the Maghreb. This hypothesis is reinforced by the results of our study. Interestingly, this study was the first that describes the HBsAg subtype prevalence in Tunisia. Subtype ayw2 was the most predominant (95.9\%), and the dominance of genotype $\mathrm{D}$ was associated with subtype ayw2, and few cases were associated with ayw3 and adw2. This result is in agreement with oth- 
er studies which reported the predominance of subtype ayw2 in Mediterranean countries [20,21].

Analysis of the 99 HBV Tunisian patients revealed several substitutions in the $S$ region that codes aa 33-226. The global prevalence of naturally occurring HBsAg variants was high (60.6\%) and indicated that HBV circulating in Tunisia could exhibit a significant proportion of $\mathrm{S} \mathrm{mu-}$ tations. Prevalence of $S$ mutants from most geographical regions is unknown; in fact, the majority of studies focused on variations in the MHR region.

The demographic and clinical characteristics of patients indicate a significant association between the occurrence of HBsAg variants and advancing age $(\geq 35$ years), irrespective of the clinical groups of patients or HBV subgenotypes. Considering the mean age of the study subjects (36 years), most of the patients were born before the national HBV vaccination program for neonates had started in 1995. Thus, it is hypothesized that most of the subjects acquire their HBV infection in the perinatal period or infancy and the duration of HBV infection is assumed to approximate their age. This could explain that older age is more associated with a longer history of HBV infection, suggesting that most variants emerge with long-term HBV disease duration host immune selective pressure.

HBsAg mutations were correlated with genotype D. This fact is explained not only by the domination of this genotype in our study, but also by its established higher variability. De Maddalena et al. [13] reported a significantly higher intragenotypic distance in genotype $\mathrm{D}$ than genotypes $A$ and $G$, especially at the 'a' determinant. Thus, it can be suggested that what is already known about the higher affinity of genotype $\mathrm{D}$ for mutations in the pre-C region can also be true for other regions [22, 23]. This hypothesis is reinforced by the results of our study. Interestingly, HBsAg mutations were correlated with subgenotype $\mathrm{D} 7$ in present data.

Naturally occurring MHR variants were $12.1 \%$. Nucleotide sequence variations in the MHR, the highly antigenic segment of HBsAg, may have important clinical features such as diagnostic problems and escape from immune recognition [24]. Thus, the prevalence and types of MHR variants are of interest. The up-to-date published data for several countries show notable differences: from 14.8\% in Argentina [25], 15\% in Morocco [20], $17.2 \%$ in Iran [26], 24\% in Japan [27], 27.2\% in Turkey [21], 27.8\% in France [28], 28\% in Taiwan [29], up to 39\% of unselected chronic carriers in Spain [30], 46.5\% in Korea [31], and $46.6 \%$ in China [32]. This variability of results about MHR substitution prevalence may be attrib- uted to differences in the genetic factors $[33,34]$ and to characteristics of populations studied. Indeed, it has been suggested that age, advanced liver disease, HBeAg-negative status, and antiviral therapy influence the occurrence of MHR mutations [35-38]. Moreover, it is essential to note that $8 \%$ of patients had mutations in the 'a' determinant of the MHR. Higher mutation frequencies of MHR variants (60\%) were observed inside the 'a' determinant, which confirm the finding of previous studies $[27,39,40]$.

A large number of MHR mutants that have been previously reported to be in association with failure of $\mathrm{HBsAg}$ detection were detected in this study (table 3). Ser143Leu/ Thr was the most common MHR variation of the studied population; this substitution is known to cause incongruity in some diagnostic assays [41, 42]. Ser143Leu was also detected in the follow-up plasma samples, suggesting that it was a stable variant [21].

In the present study, variants associated with vaccine and immunotherapy escape were found in 2 and $1 \%$ of carriers, respectively. A potential problem of patients with high viral load carrying MHR variations is the possibility of becoming the source of transmission, especially variants which could escape from vaccine-induced antibodies $[38,43]$. Thus, the great danger of vaccine escape mutants is their emergence in the general population including HBV-vaccinated individuals [44]. One of the most frequent and well-documented vaccine escape mutants is G145R [45, 46]; HBV isolates with G145R are known to be transmitted despite vaccination against $\mathrm{HBV}$ [47]. In our study, none of the patients displayed substitution G145A. However, the presence of other immune escape mutants in our population should be considered in the immunization program.

Mutation C138G associated with cysteine residues was observed in 1 patient. To our knowledge, C138G has not been previously reported. The loss of cysteine residues was notable, because this could lead to a dramatic change in the conformation of MHR and in its antigenicity [41, 48]. Interestingly, we reported a novel 24-nucleotide deletion which affected 8 aa of HBsAg from aa 110 to aa 117. Since Yamamoto et al. [49] observed the first insertion in the $S$ gene, insertion/deletion in HBsAg had been reported in various studies [50-53]. To the best of our knowledge, the present study is the first reporting an MHR deletion which affected this number of codons. Insertion or deletion in the MHR may cause the loss of conformational epitope and modify antigenicity of $\mathrm{HBsAg}$, render HBsAg undetectable, or induce immune escape variants to evade virus clearance $[52,54,55]$.
Chaouch et al. 
Our study showed that the MHR is the more conserved region in the $S$ gene, consistent with previous results showing that most occurrences of $S$ mutations were in the region outside the MHR [22, 40].

In the present data, most of the aa substitutions (79.1\%) occurred in different immune epitopes of the $S$ gene. This finding was in agreement with the results of other studies, especially in genotype $\mathrm{D}$-infected patients $[22,56]$. In our study group, nearly half of the mutations $(44.3 \%)$ occurred in the CTL epitope, suggesting a narrowly focused immune selection pressure at a hot spot position.

The role of $S$ mutations in the outcome and persistence of HBV infection remain unclear. Various studies reported a tendency for a higher prevalence of $S$ variants in patients at an advanced stage of liver disease [21,57-59] and suggest that active viral replication under host immune pressure seems to cause the accumulation of $S$ variations. However, these findings may not be conclusive in this study since the number of cirrhosis patients was small. Some $S$ mutation patterns have been found in association with cirrhosis [60-62]. In the present data, 3 mutations were detected in association with cirrhosis: one is the Y134N mutation, inside the MHR, the others are L49R and L213I mutations, outside the MHR. These mutations might play a pivotal role in the development of cirrhosis.

The polymerase gene was more conserved and not all HBsAg variants were accompanied by substitutions in the polymerase. RT domains appear constrained with only substitutions corresponding to antiviral resistance. As reported recently, HBV polymerase and surface proteins may evolve independently despite the overlapping of their genes [63].

In conclusion, a significant prevalence of naturally occurring HBsAg variants was observed among Tunisian chronic HBV carriers. Interestingly, some novel variants and mutation patterns were detected. Most of these polymorphisms are not associated with disease immune selection but with disease duration, as we found a clear association with age. Interestingly, we have shown a correlation with subgenotype D7. Based on these results, it can be concluded that natural viral variability in a geographical region and duration of infection are among the major factors associated with occurrence of S mutations. Considering that chronic carriers are the major reservoir of $\mathrm{HBV}$ infection, the selection of such variants in these patients could increase the problem of transmission of these variants in the general population. Therefore, their role in the natural course of HBV infection should be clarified, and epidemiological monitoring of naturally occurring HBsAg variants is essential, especially for immunotherapy and vaccination efficacy.

\section{Disclosure Statement}

The authors have no conflicts of interest to disclose.

\section{References}

1 Lok AS: Natural history and control of perinatally acquired hepatitis B virus infection. Dig Dis 1992;10:46-52.

2 Echevarria JM, Avellon A: Hepatitis B virus genetic diversity. J Med Virol 2006;78:36-42.

3 Norder H, Courouce AM, Coursaget P, Echevarria JM, Lee SD, Mushahwar IK, et al: Genetic diversity of hepatitis B virus strains derived worlwide: genotypes, subgenotypes and HBsAg subtypes. Intervirology 2004;47:289309.

4 Carman WF: The clinical significance of surface antigen variants of hepatitis B virus. J Viral Hepat 1997;4:11-20.

5 Cooreman MP, Leroux-Roels G, Paulij WP: Vaccine and hepatitis B immune globulin-induced escape mutations of hepatitis $B$ virus surface antigen. J Biomed Sci 2001;8:237-247.

6 Fortuin MKV, Karthigesu V, Allison L, Howard C, Hoare S, Mendy M, et al: Breakthrough infections and identification of a viral variant in Gambian children immunized with hepatitis B vaccine. J Infect Dis 1994;169:13741376.
7 Ngui SL, O'Connell S, Eglin RP, Heptonstall J, Teo CG: Low detection rate and maternal provenance of hepatitis B virus $\mathrm{S}$ gene mutants in cases of failed postnatal immunoprophylaxis in England and Wales. J Infect Dis 1997; 176:1360-1365.

8 Ijaz S, Ferns RB, Tedder RS: A ‘first loop' linear epitope accessible on native hepatitis $B$ surface antigen that persists in the face of 'second loop' immune escape. J Gen Virol 2003; 84:269-275.

9 Mancini-Bourgine $\mathrm{M}$, Fontaine $\mathrm{H}$, Brechot $\mathrm{C}$, Pol S, Michel ML: Immunogenicity of a hepatitis B DNA vaccine administered to chronic HBV carriers. Vaccine 2006;24:4482-4489.

10 Barnaba V, Franco A, Paroli M, Benvenuto R, De Petrillo G, Burgio VL, et al: Selective expansion of cytotoxic $\mathrm{T}$ lymphocytes with a CD4+CD56+ surface phenotype and a $\mathrm{T}$ helper type 1 profile of cytokine secretion in the liver of patients chronically infected with hepatitis B virus. J Immunol 1994;152:30743087.
11 Ducos J, Bianchi-Mondain AM, Pageaux G Conge AM, Poncet R, Vendrell JP, et al: Hepatitis $B$ virus (HBV)-specific in vitro antibody production by peripheral blood mononuclear cells (PBMC) after vaccination by recombinant hepatitis B surface antigen (rHBsAg). Clin Exp Immunol 1996;103:15-18.

12 Gerlich WH: Diagnostic problems caused by HBsAg mutants: a consensus report of an expert meeting. Intervirology 2004;47:310-313.

13 De Maddalena C, Giambelli C, Tanzi E, Colzani D, Schiavini M, Milazzo L, et al: High level of genetic heterogeneity in $\mathrm{S}$ and $\mathrm{P}$ genes of genotype D hepatitis B virus. Virology 2007;365:113-124.

14 Triki H, Said N, Ben Salah A, Arrouji A, Ben Ahmed F, Bouguerra A, et al: Seroepidemiology of hepatitis B, C and delta viruses in Tunisia. Trans R Soc Trop Med Hyg 1997;91: 11-14.

15 Meldal BH, Moula NM, Barnes IH, Boukef K, Allain JP: A novel hepatitis B virus subgenotype, D7, in Tunisian blood donors. J Gen Virol 2009;90:1622-1628. 
16 Hannachi N, Ben Fredj N, Bahri O, Thibault V, Ferjani A, Gharbi J, et al: Molecular analysis of HBV genotypes and subgenotypes in the Central-East region of Tunisia. Virol J 2010;7: 302.

17 Ciccozzi M, Ciccaglione AR, Lo Presti A, Equestre M, Cella E, Ebranati E, et al: Evolutionary dynamics of HBV-D1 genotype epidemic in Turkey. J Med Virol 2014;86:109116.

18 Purdy MA, Talekar G, Swenson P, Araujo A, Fields $\mathrm{H}$ : A new algorithm for deduction of hepatitis B surface antigen subtype determinants from the amino acid sequence. Intervirology 2007;50:45-51.

19 Dindoost P, Jazayeri SM, Karimzadeh H, Saberfar E, Miri SM, Alavian SM: HBsAg variants: common escape issues. Jundishapur J Microbiol 2012;5:521-527.

20 El Feydi AE, Afifi R, Derdabi O, Cherradi Y, Benazzouz M, et al: Hepatitis B genotypes/ subgenotypes and MHR variants among Moroccan chronic carriers. J Infect 2011;63:6675.

21 Sayiner AA, Ozcan A, Sengonul A: Naturally occurring MHR variants in Turkish patients infected with hepatitis B virus. J Med Virol 2008; $80: 405-410$.

22 Khedive A, Norouzi M, Ramezani F, Karimzadeh H, Alavian SM, Malekzadeh R, et al: Hepatitis B virus surface protein mutations clustered mainly in CTL immune epitopes in chronic carriers: results of an Iranian nationwide study. J Viral Hepat 2013;20:494501.

23 Zehender G, De Maddalena C, Giambelli C, Milazzo L, Schiavini M, Bruno R, et al: Different evolutionary rates and epidemic growth of hepatitis B virus genotypes A and D. Virology 2008;380:84-90.

24 Zuckerman AJ, Zuckerman JN: Molecular epidemiology of hepatitis B virus mutants. J Med Virol 1999;58:193-195.

25 Pineiro Y Leone FG, Pezzano SC, Torres C, Rodríguez CE, Eugenia Garay M, Fainboim $\mathrm{HA}$, et al: Hepatitis B virus genetic diversity in Argentina: dissimilar genotype distribution in two different geographical regions: description of hepatitis B surface antigen variants. J Clin Virol 2008;42:381-388.

26 Mohebbi SR, Amini-Bavil-Olyaee S, Zali N, Noorinayer B, Derakhshan F, Chiani M, et al: Molecular epidemiology of hepatitis B virus in Iran. Clin Microbiol Infect 2008;14:858866.

27 OguraY, KurosakiM, Asahina Y, Enomoto N, Marumo F, Sato C: Prevalence and significance of naturally occurring mutations in the surface and polymerase genes of hepatitis B virus. J Infect Dis 1999;180:1444-1451.

28 Roque-Afonso AM, Férey MP, Ly TD, Graube A, Costa-Faria L, Samuel D, et al: Viral and clinical factors associated with surface gene variants among hepatitis B virus carriers. Antivir Ther 2007;12:1255-1263.
29 Hsu HY, Chang MH, Ni YH, Chen HL: Survey of hepatitis $B$ surface variant infection in children 15 years after a nationwide vaccination programme in Taiwan. Gut 2004;53: 1499-1503.

30 Avellon A, Echevarria JM: Frequency of hepatitis $B$ virus ' $a$ ' determinant variants in unselected Spanish chronic carriers. J Med Virol 2006;78:24-36.

31 Song BC, Kim SH, Kim H, Ying YH, Kim HJ, Kim YJ, et al: Prevalence of naturally occurring surface antigen variants of hepatitis B virus in Korean patients infected chronically. J Med Virol 2005;76:194-202.

32 Shi Y, Wei F, Hu D, Li Q, Smith D, Li N, et al: Mutations in the major hydrophilic region (MHR) of hepatitis B virus genotype C in North China. J Med Virol 2012;84:19011906.

33 Wang XY, Harrison TJ, He X, Chen QY, Li GJ, Liu MH, Li H, Yang JY, Fang ZL: The prevalence of mutations in the major hydrophilic region of the surface antigen of hepatitis $B$ virus varies with subgenotype. Epidemiol Infect 2015; 143:3572-3582.

34 Liu CJ, Kao JH, Shau WY, Chen PJ, Lai MY, Chen DS: Naturally occurring hepatitis B surface gene variants in chronic hepatitis B virus infection: correlation with viral serotypes and clinical stages of liver disease. J Med Virol 2002;68:50-59.

35 Lazarevic I, Cupic M, Delic D, Svirtlih NS, Simonovic J, Jovanovic T: Prevalence of hepatitis $B$ virus MHR mutations and their correlation with genotypes and antiviral therapy in chronically infected patients in Serbia. J Med Virol 2010;82:1160-1167.

36 Kazim SN, Sarin SK, Sharma BC, Khan LA, Hasnain SE: Characterization of naturally occurring and lamivudine-induced surface gene mutants of hepatitis B virus in patients with chronic hepatitis B in India. Intervirology 2006;49:152-160.

37 Yeh CT: Development of HBV S gene mutants in chronic hepatitis B patients receiving nucleotide/nucleoside analogue therapy. Antivir Ther 2010;15:471-475.

38 Sayan M, Cavdar C, Dogan C: Naturally occurring polymerase and surface gene variants of hepatitis B virus in Turkish hemodialysis patients with chronic hepatitis B. Jpn J Infect Dis 2012;65:495-501

39 Ding F, Miao XL, Li YX, Dai JF, Yu HG: Mutations in the $\mathrm{S}$ gene and in the overlapping reverse transcriptase region in chronic hepatitis B Chinese patients with coexistence of HBsAg and anti-HBs. Braz J Infect Dis 2016; 20:1-7.

40 Abdelnabi Z, Saleh N, Baraghithi S, Glebe D, Azzeh M: Subgenotypes and mutations in the $\mathrm{S}$ and polymerase genes of hepatitis $\mathrm{B}$ virus carriers in the West Bank, Palestine. PLoS One 2014;9:113821.
41 Tian Y, Xu Y, Zhang Z, Meng Z, Qin L, Lu M, et al: The amino acid residues at positions 120 to 123 are crucial for the antigenicity of hepatitis B surface antigen. J Clin Microbiol 2007; 45:2971-2978.

42 Ireland JH, O'Donnell B, Basuni AA, Kean JD, Wallace LA, Lau GK, et al: Reactivity of 13 in vitro expressed hepatitis $B$ surface antigen variants in 7 commercial diagnostic assays. Hepatology 2000;31:1176-1182.

43 Oon CJ, Chen WN: Current aspects of hepatitis B surface antigen mutants in Singapore. J Viral Hepat 1998;5:17-23.

44 Carman WF, Trautwein C, van Deursen FJ, Colman K, Dornan E, McIntyre G, et al: Hepatitis $B$ virus envelope variation after transplantation with and without hepatitis B immune globulin prophylaxis. Hepatology 1996; 24:489-493.

45 Veropalumbo E, Marrone A, Vallefuoco L, Perruolo G, Orlando R, Scordino F, et al: Immunocompromised patients with $\mathrm{HBsAg}$ a determinant mutants: comparison of $\mathrm{HBsAg}$ diagnostic assays. Intervirology 2010;53:183187.

46 Ueda Y, Marusawa H, Egawa H, Okamoto S, Ogura Y, Oike F, et al: De novo activation of HBV with escape mutations from hepatitis B surface antibody after living donor liver transplantation. Antivir Ther 2011;16:479-487.

47 Carman WF, Zanetti AR, Karayiannis P, Waters J, Manzillo G, TanziE, et al: Vaccine-induced escape mutant of hepatitis B virus. Lancet 1990;336:325-329.

48 Mangold CM, Unckell F, Werr M, Streeck RE: Secretion and antigenicity of hepatitis small envelope proteins lacking cysteines in the major antigenic region. Virology 1995;211:535543

49 Yamamoto K, Horikita M, Tsuda F, Itoh K, Akahane Y, Yotsumoto S, et al: Naturally occurring escape mutants of hepatitis B virus with various mutations in the $S$ gene in carriers seropositive for antibody to hepatitis B surface antigen. J Virol 1994,68:2671-2676.

50 Tong W, Sun L, He J, He S, Du F: A novel nucleotide insertion in $S$ gene of hepatitis $B$ virus in a chronic carrier. Virol J 2010;7:104.

51 Hou JL, Karayiannis P, Waters J, Luo KX, Liang CS, Thomas HC: A unique insertion in the $S$ gene of surface antigen-negative hepatitis B virus Chinese carriers. Hepatology 1995 ; 21:273-278.

52 Yu DM, Li XH, Mom V, Lu ZH, Liao XW, Han Y, et al: N-glycosylation mutations within hepatitis B virus surface major hydrophilic region contribute mostly to immune escape. J Hepatol 2014;60:515-522.

53 Coleman PF: Surveillance for hepatitis B surface antigen mutants. J Med Virol 2006;78: 56-58.

54 Carman WF, Korula J, Wallace L, MacPhee R, Mimms L, Decker R: Fulminant reactivation of hepatitis $\mathrm{B}$ due to envelope protein mutant that escaped detection by monoclonal $\mathrm{HBsAg}$ ELISA. Lancet 1995;345:1406-1407. 
55 Zhou YH, Zhou JX, LI L, Bi YC, Liu Y, Pan JS, et al: A novel hepatitis B virus mutant coexisting with wild type virus in a carrier with negative $\mathrm{HBsAg}$ yet positive $\mathrm{HBeAg}$ and antiHBs. J Clin Virol 2009;46:363-366.

56 Moradi A, Zhand S, Ghaemi A, Javid N, Tabarraei A: Mutations in the $S$ gene region of hepatitis B virus genotype D in Golestan Province-Iran. Virus Genes 2012;44:382-387.

57 Coppola N, Onorato L, Minichini C, Di Caprio G, Starace M, Sagnelli C, et al: Clinical significance of hepatitis B surface antigen mutants. World J Hepatol 2015;7:2729-2739.

58 Pollicino T, Cacciola I, Saffioti F, Raimondo GJ: Hepatitis B virus PreS/S gene variants: pathobiology and clinical implications. Hepatol 2014;61:408-417.
59 Caligiuri P, Cerruti R, Icardi G, Bruzzone B: Overview of hepatitis $B$ virus mutations and their implications in the management of infection. World J Gastroenterol 2016;22:145154.

60 Lee SA, Kim K, Kim H, Kim BJ: Nucleotide change of codon 182 in the surface gene of hepatitis $\mathrm{B}$ virus genotype $\mathrm{C}$ leading to truncated surface protein is associated with progression of liver diseases. J Hepatol 2012;56: 63-69.

61 Lai MW, Huang SF, Hsu CW, Chang MH, Liaw YF, Yeh CT: Identification of nonsense mutations in hepatitis $B$ virus $S$ gene in patients with hepatocellular carcinoma developed after lamivudine therapy. Antivir Ther 2009;14:249-261.

62 Huang SF, Chen YT, Lee WC, Chang IC, Chiu YT, Chang Y, et al: Identification of transforming hepatitis $\mathrm{B}$ virus $\mathrm{S}$ gene nonsense mutations derived from freely replicative viruses in hepatocellular carcinoma. PLoS One 2014;9:e89753.
63 Zaaijer HL, Hemert FJ, Koppelman MH, Lukashov VV: Independent evolution of overlapping polymerase and surface protein genes of hepatitis B virus. J Gen Virol 2007;88:21372143.

64 Katsoulidou A, Paraskevis D, Magiorkinis E, Moschidis Z, Haida C, Hatzitheodorou E, et al: Molecular characterization of occult hepatitis B cases in Greek blood donors. J Med Virol 2009;81:815-825.

65 Pourkarim MR, Sharifi Z, Soleimani A, Amini-Bavil-Olyaee S, Elsadek Fakhr A, Sijmons $S$, et al: Evolutionary analysis of HBV 'S' antigen genetic diversity in Iranian blood donors: a nationwide study. J Med Virol 2014;86:144155. 